\title{
Difluoroboranyl derivatives as efficient panchromatic photoinitiators in radical polymerization reactions
}

\author{
Beata Jędrzejewska ${ }^{1} \cdot$ Borys Ośmiałowski $^{1}$
}

Received: 27 March 2017/Revised: 14 July 2017/Accepted: 23 September 2017/

Published online: 16 October 2017

(C) The Author(s) 2017. This article is an open access publication

\begin{abstract}
Photoinitiating systems based on $\mathrm{BF}_{2}$ derivatives and tetramethylammonium phenyltriethylborate salt were tested in photopolymerization reactions through the photo-DSC method. The good rates of TMPTA polymerization and final monomer conversion were obtained for tested system. The effect of the type of heterocycle on their properties was revealed. The excited state processes, investigated by nanosecond flash photolysis, lie on a fast excited state photoinitiated cleavage leading to reactive species. A triplet state is observed for investigated derivatives.
\end{abstract}

Keywords Polymers · Radical polymerization · Photochemistry $\cdot$ Difluoroboranyls

\section{Introduction}

Compounds containing $\mathrm{BF}_{2}$ moiety are a class of fluorescent dyes. They are usually characterized by: (a) high extinction coefficient, (b) high fluorescence quantum yield, (c) narrow emission band, (d) relatively long excited-state lifetime, (e) great photostability and (f) large two-photon absorption cross-section [1-3]. The photophysical and photochemical properties of the fluorescent difluoroboranyl dyes can be easily modified, e.g. by an introduction of the suitable substituent [2], by

Electronic supplementary material The online version of this article (doi:10.1007/s00289-017-22011) contains supplementary material, which is available to authorized users.

Beata Jędrzejewska

beata@utp.edu.pl

1 Faculty of Chemical Technology and Engineering, UTP University of Science and Technology, Seminaryjna 3, 85-326 Bydgoszcz, Poland 
altering atoms through, which the $\mathrm{BF}_{2}$ group is attached to the molecule $[4,5]$ or by changing the conjugation path $[6,7]$ or their structure from symmetrical to unsymmetrical one [8-10]. Among various compounds carrying the $\mathrm{BF}_{2}$ moiety the most common are boron-dipyrromethenes (BODIPYs) $[8,11]$. The core of the dyes is a complex of dipyrromethane with a disubstituted boron atom, typically a $\mathrm{BF}_{2}$ unit [12]. This means that $\mathrm{BF}_{2}$ group is attached to two nitrogen atoms. Another examples are $\beta$-diketonate $\left(\mathrm{OBF}_{2} \mathrm{O}\right)$ and $\beta$-ketoiminate $\left(\mathrm{NBF}_{2} \mathrm{O}\right)$ difluoroboranyls [13]. Their easy functionalization makes the dyes very attractive as immobilized [13] probes or indicators [2, 14], as dyes for biolabelling [15], chemodosimeters [16]. They also are used in solar cells applications [17]. Furthermore, they can find an application in the other fields of technology making use of interaction of light with matter.

Polymerization is any process of converting monomer molecules into linear chains or three-dimensional network of polymer chains [14, 15]. A lot of studies have been published in this area because polymerization process is very important from practical viewpoint. There are many kinds of polymerization and different systems exist to categorize them. Photopolymerization is one of the most important processes in that field. It makes use of radiation in the ultraviolet (UV) or visible (Vis) range of light to generate reactive species such as radicals or ions $[16,17]$ that reacts in a chain reaction. Thus, the photoinitiation of polymerization requires the presence of molecule capable of absorbing light of the appropriate wavelength (photoinitiator, PI) and generating reactive species alone. Moreover, radicals or ions can be formed by primary or subsequent reactions involving, beside PI, one or more additional compounds (photoinitiating system, PIS). Photoinitiated radical polymerization, which is one of the most common and useful polymerization reactions, may be initiated by one-component system leading to homolytic cleavage process (type I PI) or by two-component systems producing radicals through a hydrogen transfer, an electron/proton transfer or an energy transfer (type II PI). The type II PIs are generally composed of PI and either a hydrogen donor (HD) or a photosensitizer (PS) [18-22]. One- and two-component systems are also used to start photoinduced cationic polymerization. Classical cationic PIs are onium salts [23].

The light-induced polymerization reactions are very important in different industrial sectors, such as radiation curing, imaging, microelectronics, medicine or optics [15]. The development of high-performance PISs operating upon visible light exposure is still a challenge. Recently Lalevée et al. [15, 24] have reported the photoinitiators based on the BODIPY and boranil chromophores. These dyes are characterized by high tunability of the absorption allowing triggering the cationic polymerization at any wavelengths in the 400-600 nm range. Upon visible light exposure these dyes are able to photosensitize the iodonium salt decomposition. This results in the formation of radical cation of the dye $\left(\right.$ dye $\left.^{+}\right)$and aryl radical of the iodonium salt (Ar.) and then by subsequent reactions leads to cationic polymerization of epoxy, epoxy-silicone and vinyl ether monomers [24, 25]. What is more, the addition of silanes to the BODIPY/iodonium salt couples increases the efficiency of the polymerization. The boron-dipyrromethenes were also introduced in PISs in combination with a photoacid generator for the design of photoresists. On the other hand, the three-component system boranil/methyldiethanolamine/ 
phenacylbromide or pyrromethane dye/amine/triazine derivatives were proposed as PISs for radical photopolymerization. However, they initiated trimethylolpropane triacrylate (TMPTA) polymerization with low final conversions [18].

The present study was undertaken to reveal the polymerization initiation ability of new photoinitiating system based on difluoroboranyl dyes of the type $\mathrm{NBF}_{2} \mathrm{O}$ and phenyltriethylborate salt. Our intention was to show that panchromatic sensibilization of radical polymerization can be achieved by benzannulation of the parent dye.

\section{Experimental}

\section{Materials and methods}

The general method of the synthesis of tetramethylammonium phenyltriethylborate salt (B6) and dyes 1, 2, 3 and 4 together with their spectral characteristic are described elsewhere [26-30]. Solvents and monomers [trimethylolpropane triacrylate (TMPTA), 1,6-hexanediol diacrylate (HDODA), lauryl acrylate (LA)] were obtained commercially from Aldrich Chemical Co. and used as received.

Absorption and fluorescence spectra were measured with a Shimadzu UV-Vis Multispec-1501 spectrophotometer, and a Hitachi F-4500 spectrofluorimeter, respectively. The nanosecond laser flash photolysis experiments were performed using a LKS.60 Laser Flash Photolysis apparatus (Applied Photophisics). Laser irradiation at $355 \mathrm{~nm}$ from the third harmonic of the Q-switched Nd:YAG laser from a Lambda Phisik/model LPY 150 operating at $65 \mathrm{~mJ}$ pulse $^{-1}$ (pulse width about 4-5 ns) was used for the excitation. Transient absorbances at pre-selected wavelengths were monitored by a detection system consisting of a monochromator, a photomultiplier tube (Hamamatsu R955) and a pulsed xenon lamp (150 W) as a monitoring source. The signal from the photomultiplier was processed by a HelwettPackard/Agilent an Agilent Infiniium 54810A digital storage oscilloscope and an Acorn compatible computer.

The electrochemical characteristics of the compounds were investigated using a cyclic voltammetry (Electroanalytical Cypress System Model CS-1090) employing a $1 \mathrm{~mm}$ platinum electrode as working electrode, a platinum wire as counter electrode and an $\mathrm{Ag} / \mathrm{AgCl}(3.0 \mathrm{M} \mathrm{KCl})$ electrode as reference electrode. The cyclic voltammograms were obtained from a one-compartment glass cell in $0.1 \mathrm{M}$ tertrabutylammonium perchlorate as a supporting electrolyte, where the scan rate was 100 or $400 \mathrm{mV} \mathrm{s}^{-1}$.

The investigation of the polymerization kinetics was based on the measurements of the rate of the heat evolution during the chain reaction in thin film cured sample $(0.035 \pm 0.002 \mathrm{~g})$ using photo-DSC apparatus constructed on the basis of a TA Instruments DSC 2010 Differential Scanning Calorimeter. Irradiation of the polymerization mixture was performed using a diode pumped solid state (DPSS) laser (line at $473 \mathrm{~nm}$ ) with the intensity of light of $100 \mathrm{~mW} \mathrm{~cm}^{-2}$ (or a DPSS laser line at $457 \mathrm{~nm}$ with the intensity of light of $150 \mathrm{~mW} \mathrm{~cm}^{-2}$; or an argon ion laser Model Melles Griot 43 series line at $488 \mathrm{~nm}$ with the intensity of light of $100 \mathrm{~mW} \mathrm{~cm}^{-2}$ ). Polymerization solution was composed of $\gamma$-butyrolactone $(1 \mathrm{~mL})$, 
2-ethyl-2-(hydroxymethyl)-1,3-propanediol triacrylate (TMPTA; $9 \mathrm{~mL}$ ), difluoroboranyl derivative $\left(A_{473 \mathrm{~nm}}=2\right)$ and $\mathbf{B 6}(0.003 \mathrm{M})$. A reference formulation did not contain an electron donor (B6).

The rate of polymerization $\left(R_{\mathrm{p}}\right)$, the conversion of the vinyl groups $(C)$ and the quantum yield of polymerization $\Phi_{\mathrm{p}}$ were determined based on the well known equations [31-33].

\section{Results and discussion}

We focused our attention on the possibility of an application of difluoroboranyl dyes as a component in the photoinitiating systems for the polymerization of acrylic monomers. The tested difluoroboranyl derivatives (dyes 1, 2, 3 or 4) were applied as visible light absorbing molecules in the presence of phenyltriethylborate tetramethylammonium salt (B6) used as an efficient electron donor in the excited state (see Fig. 1).

The crucial parameters in photopolymerization are a compatibility of the PIS absorption spectrum with an emission spectrum of the light source and the number of available incident photons. Thus, the spectral properties of the PI have a big impact on the polymerization rate, $R_{\mathrm{p}}$, which is directly connected with the amount of light absorbed [34]. As shown in Figs. S1 and S2 (in Supporting Information), the difluoroboranyls exhibit absorption in the visible wavelength range (for $\lambda_{\max }$ see Table 1), which allows a good matching with the visible-light emission of various sources, for example, diode lasers at $\lambda=408,457$ or $473 \mathrm{~nm}$. At these irradiation wavelengths the electron donor is transparent.

For tested photoinitiator systems we assumed that the initiation of polymerization proceeds by an electron transfer mechanism. The electron transfer from the borate salt to the excited difluoroboranyls is feasible if the change of the free enthalpy for the photoinduced electron transfer (PET) process $\left(\Delta G_{\mathrm{el}}\right)$ is negative $[35,36]$. The $\Delta G_{\mathrm{el}}$ values for the tested photoredox pairs were estimated on the basis of the oxidation potential $\left(E_{\mathrm{ox}}\right)$ of the borate salt, singlet $\left(E_{00}\right)$ and triplet $\left(E^{T}\right)$ state energy of the dyes and their reduction potential $\left(E_{\text {red }}\right)$ using Rehm-Weller equation
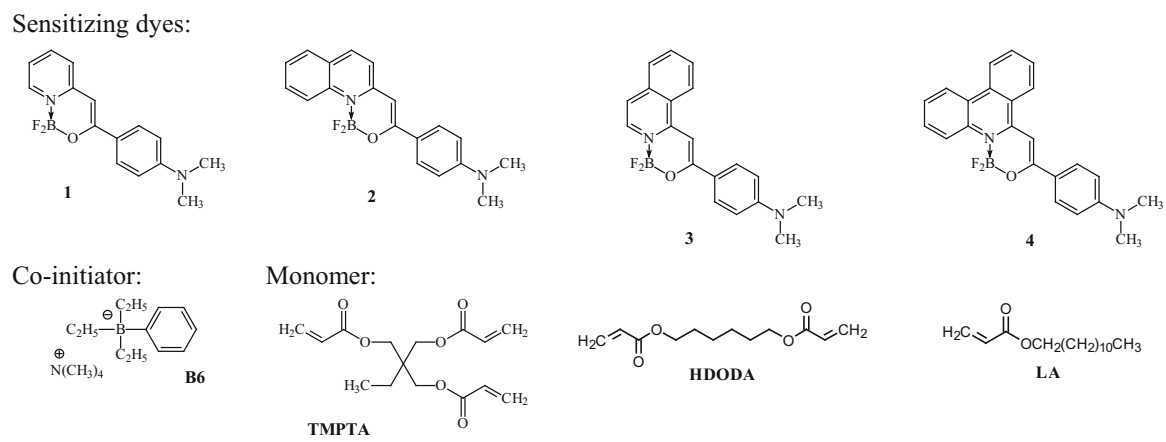

Fig. 1 Structures of the sensitizing dyes, co-initiator and monomers under the study 
Table 1 Spectral characteristic of difluoroboranyl derivatives in ethyl acetate (EtOAc)

$\left(\lambda_{\mathrm{ex}}=404 \mathrm{~nm}\right.$ for $\mathbf{1 ,} 2$ and $\mathbf{3}$, and $\lambda_{\mathrm{ex}}=450 \mathrm{~nm}$ for 4 )

Absorption $\left(\lambda_{\max }^{a b} ; \mathrm{nm}\right)$,

fluorescence maxima $\left(\lambda_{\max }^{\mathrm{fl}} ; \mathrm{nm}\right)$,

Stokes shift $\left(\Delta v ; \mathrm{cm}^{-1}\right)$,

maximum extinction coefficient

( $\varepsilon ; 10^{4} \mathrm{M}^{-1} \mathrm{~cm}^{-1}$ ), fluorescence

quantum yield $\left(\phi_{\mathrm{fl}}\right)$,

fluorescence lifetimes ( $\tau$; ps),

their amplitudes $(\alpha)$, average

lifetime, $\tau_{\mathrm{av}}$ calculated as

$\tau_{\mathrm{av}}=\left(\Sigma_{i} \alpha_{i} \tau_{i}\right) /\left(\Sigma_{i} \alpha_{i}\right)$, radiative

$\left(k_{\mathrm{r}} ; 10^{8} \mathrm{~s}^{-1}\right)$ and non-radiative

$\left(k_{\mathrm{nr}} ; 10^{8} \mathrm{~s}^{-1}\right)$ rate constants and singlet $\left(E_{00}\right)$ and triplet $\left(E^{T}\right)$

state energy

\begin{tabular}{lllll}
\hline & $\mathbf{1}$ & $\mathbf{2}$ & $\mathbf{3}$ & $\mathbf{4}$ \\
\hline$\lambda_{\max }^{a b}(\mathrm{~nm})$ & 416 & 468 & 458 & 475 \\
$\varepsilon\left(10^{4} \mathrm{M}^{-1} \mathrm{~cm}^{-1}\right)$ & 3.67 & 4.52 & 3.03 & 6.41 \\
$\lambda_{\max }^{\mathrm{fl}}(\mathrm{nm})$ & 499 & 534 & 520 & 536 \\
$\Delta v\left(\mathrm{~cm}^{-1}\right)$ & 3998 & 2641 & 2603 & 2396 \\
$\phi_{\mathrm{fl}}$ & 0.699 & 0.614 & 0.663 & 0.655 \\
$\tau_{1}^{\mathrm{fl}}(\mathrm{ns})$ & 0.442 & 0.358 & 0.255 & 0.314 \\
$\alpha_{1}(\%)$ & 3.76 & 3.41 & 3.40 & 2.69 \\
$\tau_{2}^{\mathrm{fl}}(\mathrm{ns})$ & 2.647 & 2.777 & 2.695 & 2.746 \\
$\alpha_{2}(\%)$ & 96.24 & 96.59 & 97.6 & 97.31 \\
$\tau_{a v}^{\mathrm{fl}}(\mathrm{ns})$ & 2.56 & 2.69 & 2.61 & 2.68 \\
$k_{\mathrm{r}}\left(10^{8} \mathrm{~s}^{-1}\right)$ & 2.73 & 2.28 & 2.54 & 2.45 \\
$k_{\mathrm{nr}}\left(10^{8} \mathrm{~s}^{-1}\right)$ & 1.17 & 1.43 & 1.29 & 1.29 \\
$\lambda_{00}(\mathrm{~nm})$ & 456.6 & 496.9 & 489.2 & 501.2 \\
$E_{00}(\mathrm{eV})$ & 2.716 & 2.495 & 2.535 & 2.474 \\
$\lambda_{\mathrm{T}}(\mathrm{nm})$ & 511 & 560 & 535 & 570 \\
$E^{T}(\mathrm{eV})$ & 2.43 & 2.21 & 2.32 & 2.18 \\
\hline & & & &
\end{tabular}

[37]. The obtained data are collected in Table 2. The reduction potential of the dyes and the oxidation potential of the borate salt were measured by cyclic voltammetry. The oxidation potential of the B6 is $0.764 \mathrm{~V}$, the excitation energies of the sensitizers and their reduction potentials are summarized in Tables 1 and 2. The values of $\Delta G_{\mathrm{el}}$ for tested photoinitiating systems oscillate in the range from -0.778 to $-0.990 \mathrm{eV}$ for the $S_{1}$ excite state and from -0.480 to $-0.701 \mathrm{eV}$ for the $\mathrm{T}_{1}$ excited state. The calculations clearly show that the electron transfer in both the singlet (S) and triplet (T) excited states of the difluoroboranyls-B6 systems is thermodynamically favorable and suggest that the photoredox pairs should effectively generate free radical initiating polymerization of acrylic monomers.

The good polymerization profiles were obtained using two-component systems containing difluoroboranyl dyes and B6 upon blue light irradiation (Fig. 2). The formation of the polyacrylate network was easily characterized by measuring photopolymerization exotherms using photo-DSC apparatus. The polymerization under UV-Vis light irradiation in the presence of tested difluoroboranyls without a co-initiator was not observed.

The heterocyclic ring in the difluoroboranyl dyes affects the initiating ability of these two-component systems with a reactivity following the order: $\mathbf{3}, \mathbf{2}, \mathbf{4}$, and $\mathbf{1}$. These results highlight the interest of an appropriate selection of the difluoroboranyl derivatives to improve the polymerization process. For the best initiating system $\left(0.001 \mathrm{M} 3+0.0075 \mathrm{M} \mathbf{B 6} ; I_{0}=100 \mathrm{~mW} \mathrm{~cm}^{-2}\right.$ at $\left.488 \mathrm{~nm}\right)$, the polymerization rate is ca. $15 \mu \mathrm{mol} \mathrm{s}{ }^{-1}$, the conversion of carbon-carbon double bonds reaches about $70 \%$ after $60 \mathrm{~s}$ of irradiation. Figures 3 and S3 illustrate the photo-DSC profiles of TMPTA and HDODA initiated by $\mathbf{1 + B 6}, \mathbf{2}+\mathbf{B 6}, \mathbf{3}+\mathbf{B 6}$ and $\mathbf{4}+\mathbf{B 6}$ systems. The obtained data are collected in Table S2 in SI. 


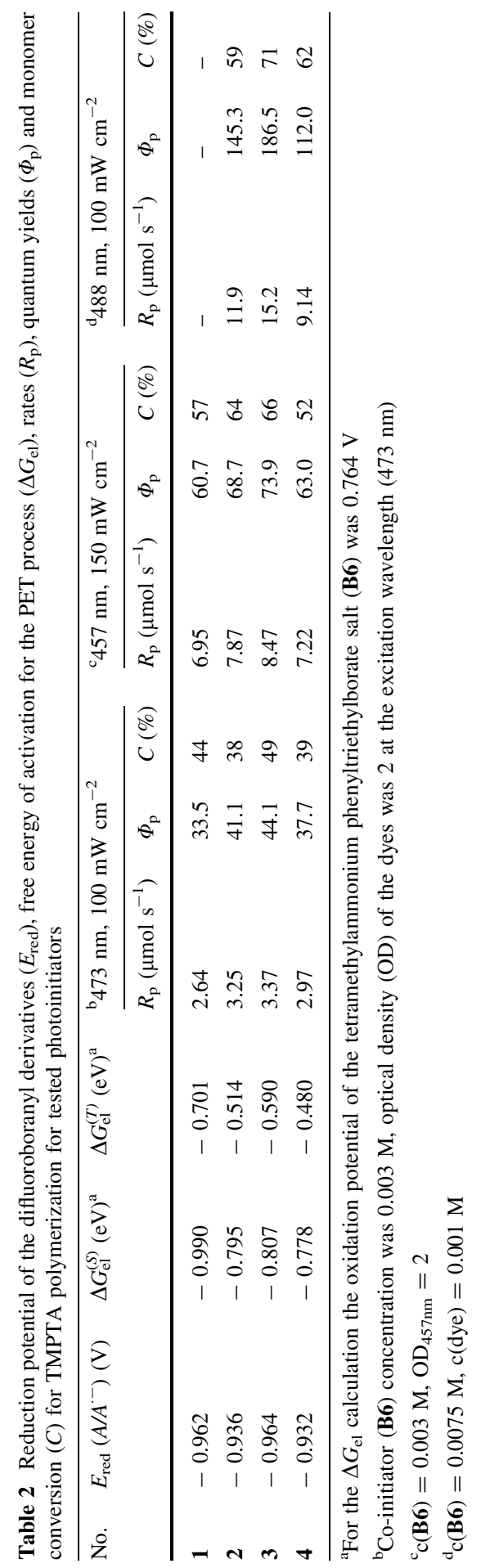


Fig. 2 Family of kinetic curves recorded by the measurements of the heat flow emitted during the photoinitiated polymerization of the TMPTA initiated by difluoroboranyl derivative - phenyltriethylborate salt marked in figure. The optical density of the photoinitiator was 2 , $I_{0}=100 \mathrm{~mW} \mathrm{~cm}^{-2}$ at $473 \mathrm{~nm}$. The applied systems possess different $\mathrm{BF}_{2}$-dyes and the identical borate salt

Fig. 3 Rate vs. conversion for photopolymerization initiated by 1+B6, 2+B6, 3+B6 and 4+B6, cured at r.t. by visible light $(457 \mathrm{~nm})$ with an intensity of $150 \mathrm{~mW} \mathrm{~cm}^{-2}$. The optical density of the photoinitiator was 2 , the B6 concentration was $0.005 \mathrm{M}$ (solid line denotes data of TMPTA polymerization; dash line-HDODA polymerization)
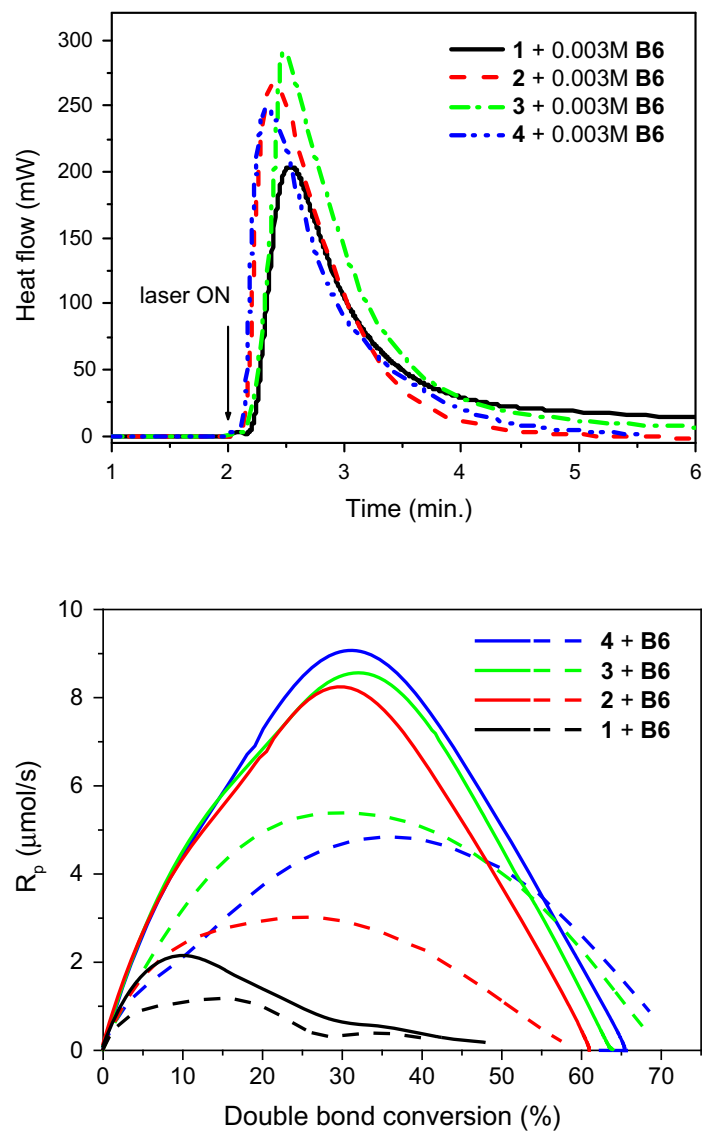

Fig. 4 Comparison of photoinitiating abilities of photoinitaing systems based on difluoroboranyls-

phenyltriethylborate salt (B6) to analogous systems containing suitable styryl dyes as a sensitizer (structures presented in SI). The optical density of the photoinitiator was 2 ,

$I_{0}=150 \mathrm{~mW} \mathrm{~cm}^{-2}$ at $457 \mathrm{~nm}$, the $\mathbf{B 6}$ concentration was $0.003 \mathrm{M}$

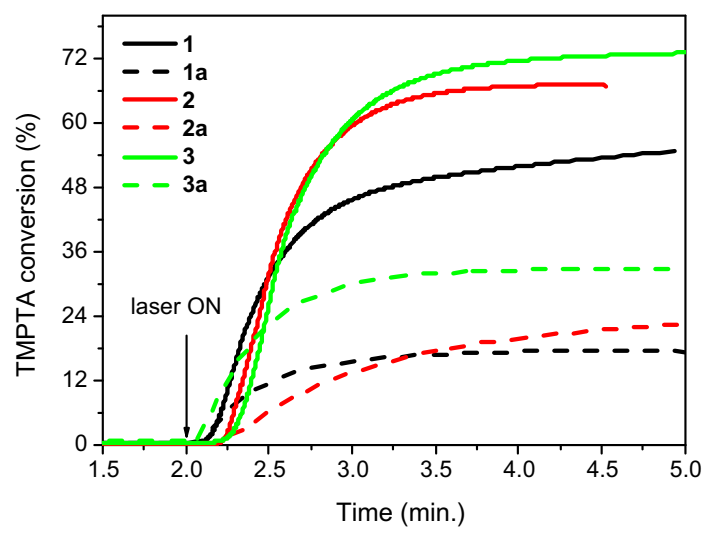

Based on the kinetic data presented in Figs. 4 (for structures 1a-3a see Table S1) and $\mathrm{S} 4$, it is also seen that the rigidity of the sensitizer molecules by introduction of $\mathrm{BF}_{2}$ unit increases significantly the photoinitiating ability of the tested systems. The 
observed rates of polymerization and monomer conversion (for the same experimental conditions) are about 2.5 times higher than that observed for styryl dyes-borate salts for which these parameters are in range from 1.21 to $3.98 \mu \mathrm{mol}$ $\mathrm{s}^{-1}$, and from 12 to $30 \%$, respectively. Therefore, tested difluoroboranyls appear to be highly efficient to photosensitize the tetramethylammonium phenyltriethylborate salt decomposition.

It must be pointed out, that not only photoinitiator type influences the photoinitiating ability but also a relative amount of the dye in the solution (Fig. S5 in SI). Our studies have shown that the highest rates of polymerization, for a given condition, were achieved at the initiator concentration related to the optical density that equals 2 . For this condition, almost whole incident light is absorbed across the entire polymerizing formulation layer. Furthermore, the TMPTA final conversion is dependent on the co-initiator concentration in the polymerizing formulation and increases from ca. 25-35 to 55-70\% with an increase in the B6 content of about 7.5 times (Figs. S6, S7 in SI).

The photoinitiating abilities of the systems composed of difluorobaranyls and phenyltriethylborate salt are comparable to the commercial photoinitiators for acrylates photopolymerization such as Irgacure 819 [BAPO; bis(2,4,6-trimethylbenzoyl)-phenylphosphineoxide] and Darocur TPO [TMDPO; diphenyl(2,4,6trimethylbenzoyl)-phosphine oxide]. For example, as it is known from Arsu et al. studies [38], for one-component photoinitiating system based on either TMDPO or BAPO, the degree of double bond conversion in TMPTA is equal $30 \%$, and $40 \%$ for addition of mercaptothioxanthone (TX-SH) to the initiator formulation [38]. According to Fouassier et al. [39], photopolymerization profile of TMPTA in laminate in the presence of the commercial photoinitiator BAPO on the exposure to

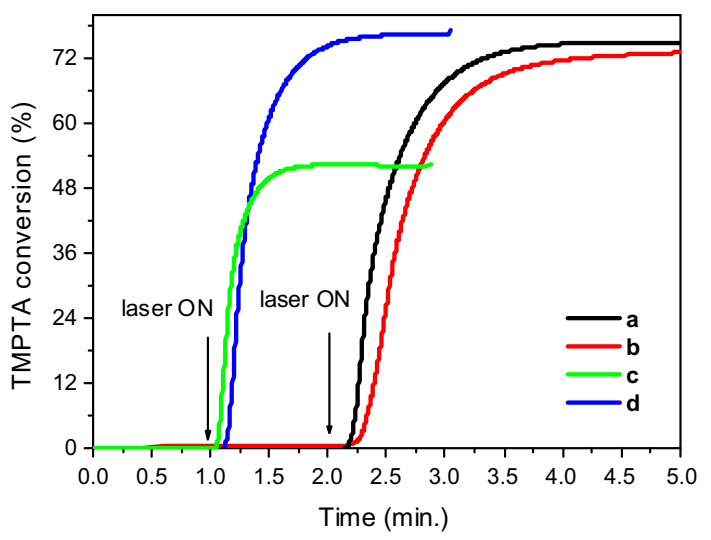

Fig. 5 Comparison of the TMPTA polymerization initiated by following systems: a $3(0.001$ M) + B6 $(0.0075 \mathrm{M})$, laser beam $\lambda=488 \mathrm{~nm} 100 \mathrm{~mW} \mathrm{~cm}^{-2}$, solvent: $\gamma$-butyrolactone; b $3\left(A_{457 \mathrm{~nm}}=2\right)+$ B6 $(0.0075 \mathrm{M})$, laser beam $\lambda=457 \mathrm{~nm} 150 \mathrm{~mW} \mathrm{~cm}^{-2}$, solvent: $\gamma$-butyrolactone; c DIBF (5,7-diiodo-3butoxy-6-fluorone, $\quad 0.001 \mathrm{M})+\mathbf{N P G} \quad(N$-phenylglycine, $\quad 0.01 \mathrm{M}), \quad$ laser $\quad$ beam $\lambda=488 \mathrm{~nm} 100 \mathrm{~mW} \mathrm{~cm}^{-2}$, solvent: 1-methyl-2-pyrrolidinone; d titanocene $\left[\mathrm{Ti}\left(\mathrm{C}_{6} \mathrm{~F}_{5}\right)_{2}\left(\mathrm{C}_{5} \mathrm{H}_{4}\right)_{2}\right.$, $0.001 \mathrm{M}$ ], laser beam $\lambda=488 \mathrm{~nm} 100 \mathrm{~mW} \mathrm{~cm}^{-2}$, solvent: 1-methyl-2-pyrrolidinone. Arrows indicate start of irradiation 
LED at $405 \mathrm{~nm}$ indicates $56 \%$ of monomer conversion. As illustrated in Figs. 5 and $\mathrm{S} 8$, when using the laser at $488 \mathrm{~nm}$ the photoinitiating system composed of difluoroboranyl $\mathbf{3}$ and B6 is capable of initiating the TMPTA polymerization with similar degree of double bonds conversion (ca. 70\%) to the popular one-component visible light initiator-titanocene but led to relatively lower polymerization rates (15 vs. $29 \mu \mathrm{mol} \mathrm{s}^{-1}$ ). It is also noteworthy that the $\mathbf{3}-\mathbf{B 6}$ photoredox pair exhibits only slightly worse photoinitiating ability with lower polymerization rates but higher conversion than two-component system based on common triplet state photoinitiator (DIBF-NPG).

From the comparison, it seen that, the new photoinitiating systems are efficient and yielded good final conversion of TMPTA, which endows the system with potential applications in the manufacture of coatings. Furthermore, during the photopolymerization, a noticeable bleaching of the dyes in the presence of B6 was observed. The said loss of color indicates that, beside the initiation of radical polymerization, PET process in the donor-acceptor systems leads to the bleaching of the primary absorber.

According to the general equation (Eq. 1) [40], the polymerization rate $\left(R_{\mathrm{p}}\right)$ depends on the square root of the absorbed light intensity $\left(I_{\mathrm{a}}\right)$ and is directly proportional to the monomer concentration $([M])$.

$$
R_{\mathrm{p}}=-\frac{\mathrm{d}[M]}{\mathrm{d} t}=k_{\mathrm{p}}\left(\frac{\phi_{\mathrm{d}} I_{\mathrm{a}}}{2 k_{\mathrm{t}}}\right)^{0.5}[M] .
$$

Analysis of the kinetics of radical polymerization indicates that the linear relationship is observed when one radical obtained after PET is an initiating radical while the second type of radical terminates the chain [35]. Figure 6 presents relationship between the rate of TMPTA polymerization as a function of power of laser beam. The observed trend is in good accordance with Eq. (1). The polymerization rates are proportional to the $I_{0}$ square root. This observation shows that the light intensity has no effect on the quantum yield of free radical formation $\phi$

Fig. 6 The rate of polymerization vs. light intensity for the 4-B6 system (photoinitiator concentration $=0.001 \mathrm{M}$ )

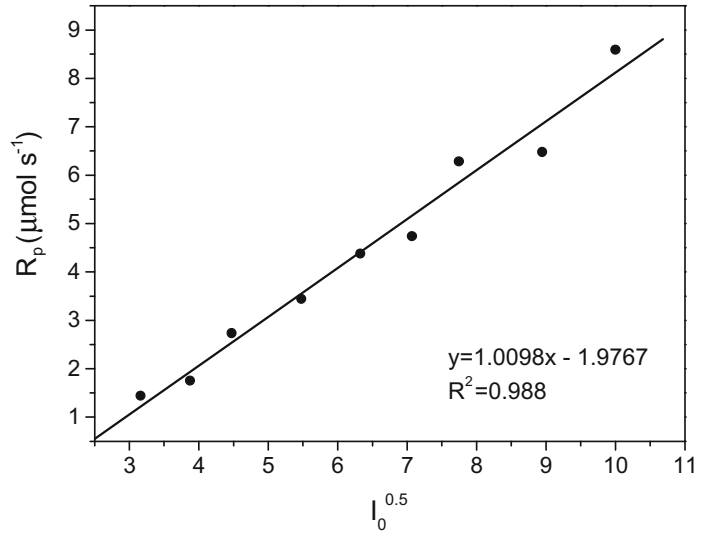


[41] and suggests that the polymerization follows a typical radical chain mechanism with second-order termination [35].

It is well-known that the alkyl radical formed from borate salts as a results of the electron transfer from borate anion to the excited state of sensitizer leading to boranyl radical followed by its decomposition initiates radical polymerization of acrylates $[42,43]$. To study the photochemical process that occurs in the excited state of the difluoroboranyl complexes, the nanosecond laser flash photolysis was used. Transient absorption spectra of the tested dyes have been performed in acetonitrile at room temperature, on exciting at $355 \mathrm{~nm}$ (see Fig. 7 for compound 4 and Fig. S9 in SI). For 4, the bleaching in the range $400-500 \mathrm{~nm}$ is formed immediately after excitation, coupled with a transient absorption growing at wavelengths longer than $500 \mathrm{~nm}$. The bleaching band is probably due to the depletion of ground state of the difluoroboranyl. The same trend was observed for compounds 1, 2 and $\mathbf{3}$ (see Fig. S9 in SI). The positive absorption band observed in helium-saturated acetonitrile solution exhibits a maximum at ca. 520-570 nm (Figs. 7, S9). Based on the literature data connected with triplet state absorption spectra of BODIPY derivatives [44-50] this band may be attributed to the triplet state of currently investigated complexes.

Absorption of the $T_{1}$ state decays completely in $5 \mu$ s after the excitation in a firstorder kinetics. The triplet-state lifetimes were determined as 2.3, 2.7, 2.3, and $2.1 \mu \mathrm{s}$, for $\mathbf{1}, \mathbf{2}, \mathbf{3}$ and $\mathbf{4}$, respectively, which is much shorter than a classical BODIPYs, e.g. trans-bis(trialkylphosphine) bisacetylide complex with BODIPY ligand (not styrylBODIPY ligand, $\tau_{\mathrm{T}}=128 \mu \mathrm{s}$ ) [51] or a $\mathrm{C}_{60}$-styrylBODIPY dyad $(71-123 \mu \mathrm{s})$ [52]. However, this lifetime is close to that observed with heavy atom effect $\left(\tau_{\mathrm{T}}=1.8 \mu \mathrm{s}\right)$ [53] or trans-bis-(trialkylphosphine) $\mathrm{Pt}(\mathrm{II})$ bisacetylide binuclear complex with BODIPY ligand $\left(\tau_{\mathrm{T}}=5.8 \mu \mathrm{s}\right.$ ) [54]. It is fair to mention that the spectra are noisy and difficult to more precise interpretation.

The triplet state of the difluoroboranyls is quenched by tetramethylammonium phenyltriethylborate salt (B6) with a concomitant observation of absorptions at 550-570 nm (see Figs. S10, S11 in SI). Figure S11 presents a transient absorption kinetic curve at $1 \mu$ s after pulse for compound $\mathbf{4}$ in deoxygenated solution without and with the presence of borate salt B6. Taking into account the $T_{1}$ state lifetime in

Fig. 7 Transient absorption spectra of $\mathbf{4}$ in helium-saturated acetonitrile recorded at a different time after the pulse assigned to the triplet state

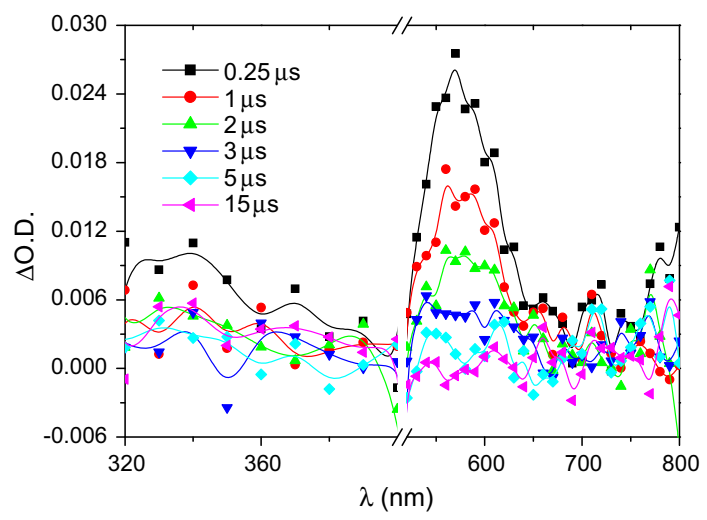


the presence of borate salt $\mathbf{B 6}$ and its concentration in the solution, the rate constant of $\mathrm{T}_{1}$ state quenching $\left(k_{\mathrm{q}}\right)$ was estimated based on the classical Stern-Volmer plot (Fig. 8).

Assuming that the electron transfer is the only quenching process of the difluoroboranyls, the electron transfer rate constants $\left(k_{\mathrm{el}}\right.$ 's) are equal to those of triplet quenching [35]. According to the data shown in Fig. 8, the quenching rates $\left(k_{\mathrm{q}}\right)$ are affected by the heterocycle ring in the dye molecule and are lower than the rate constant of the diffusion controlled reaction. For the tested photoinitiating systems, the triplet state of compound $\mathbf{3}$ was the most effectively quenched by B6. The slowest electron transfer rate was determined for dye 1-B6 photoredox pair. These results demonstrate that the quenching rates are in quite good agreement with polymerization data (see polymerization rates collected in Table 2). Thus, for more effective photo initiating system higher quenching rate was observed.

The obtained results confirmed that tested difluoroboranyl dye-phenyltriethylborate salt photoredox pairs are efficient initiators of free radical polymerization initiated by the light in visible region. Having in mind a wide range of developed applications, there are a lot of advantages of such a panchromatic sensibilization, e.g.: (1) more efficient utilization of mercury lamp due to the absorption of visible photons by a UV-Vis PI, (2) the possibility to use lasers as a light source which gives a better matching of the emission spectrum of the emitter to the absorption spectrum of the sample, (3) the opportunity to use the sunlight for polymer curing [54]. It is also common that the spectral properties of organic compounds and difluoroboranyls may be turned by a variety of methods [26]. However, our previous studies revealed that the influence of the substituent on the main absorption band is limited [26-28]. In this work, we demonstrated that an extension of the spectral sensitivity to visible lights might be achieved by benzannulation. As shown in Table 1, the absorption maximum shifts to the red of about 42-59 $\mathrm{nm}$ depending on the position of the benzannulation and the number of aromatic rings adapting the difluoroboranyls to irradiation with light emitting diodes (LEDs), diode-pumped solid-state lasers (DPSSLs) and other conventional light sources. Furthermore, extension of the spectral sensitivity does not reduce the photochemical reactivity of

Fig. 8 Concentration dependence of the triplet decay rate of the difluoroboranyls tested in acetonitrile in the presence of borate salt (B6)

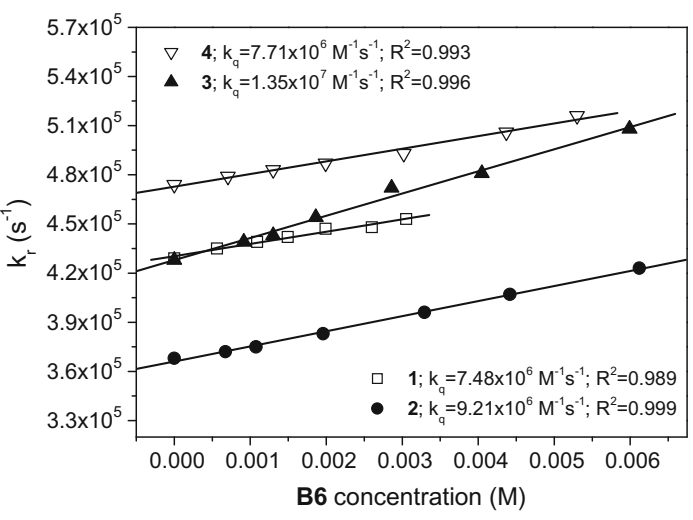


these systems, but it increases the polymerization rate and the double bonds conversion of the monomer.

Our studies also revealed that crucial effects on polymerization rate have the concentration of both components of the photoinitiating systems and the light intensity. It was found that the addition of an electron donor to the composition accelerates the chain reaction. Furthermore, laser flash photolysis experiments showed the excited singlet state of the difluoroboranyls may undergo intersystem crossing to give the excited triplet state $\left({ }^{3} \mathrm{PI}\right) .{ }^{3} \mathrm{PI}$ interacts with borate salt to produce reactive species. Rate constants $\left(k_{\mathrm{q}}\right)$ for the quenching of the excited states of the dyes were low, below diffusion controlled limits and they were dependent on the heterocyclic ring in the sensitizer molecule.

Acknowledgements Financial support from the National Science Centre in Cracow (Grant no. 2013/09/ B/ST5/03550) is gratefully acknowledged.

Open Access This article is distributed under the terms of the Creative Commons Attribution 4.0 International License (http://creativecommons.org/licenses/by/4.0/), which permits unrestricted use, distribution, and reproduction in any medium, provided you give appropriate credit to the original author(s) and the source, provide a link to the Creative Commons license, and indicate if changes were made.

\section{References}

1. Yılmaz H, Küçüköz B, Sevinç G, Tekin S, Yaglioglu HG, Hayvali M, Elmali A (2013) The effect of charge transfer on the ultrafast and two-photon absorption properties of newly synthesized borondipyrromethene compounds. Dyes Pigm 99:979-985. doi:10.1016/j.dyepig.2013.07.036

2. Zakrzewska A, Zaleśny R, Kolehmainen E, Ośmiałowski B, Jędrzejewska B, Ågren H, Pietrzak M (2013) Substituent effects on the photophysical properties of fluorescent 2-benzoylmethylenequinoline difluoroboranes: a combined experimental and quantum chemical study. Dyes Pigm 99:957-965. doi:10.1016/j.dyepig.2013.08.002

3. Wang D, Fan J, Gao X, Wang B, Sun S, Peng X (2009) Carboxyl BODIPY dyes from bicarboxylic anhydrides: one-pot preparation, spectral properties, photostability, and biolabeling. J Org Chem 74(20):7675-7683. doi:10.1021/jo901149y

4. Fan G, Yang L, Chen Z (2014) Water-soluble BODIPY and aza-BODIPY dyes: synthetic progress and applications. Front Chem Sci Eng 8:405-417. doi:10.1007/s11705-014-1445-7

5. Jędrzejewska B, Zakrzewska A, Mlostoń G, Budzák Š, Mroczyńska K, Grabarz AM, Kaczorowska MA, Jacquemin D, Ośmiałowski B (2016) Synthesis and photophysical properties of novel donoracceptor $N$-(pyridin-2-yl)-substituted benzo(thio)amides and their difluoroboranyl derivatives. J Phys Chem A 120:4116-4123. doi:10.1021/acs.jpca.6b04004

6. Papalia T, Siracusano G, Colao I, Barattucci A, Aversa MC, Serroni S, Zappalà G, Campagna S, Sciortino MT, Puntoriero F, Bonaccorsi P (2014) Cell internalization of BODIPY-based fluorescent dyes bearing carbohydrate residues. Dyes Pigm 110:67-71. doi:10.1016/j.dyepig.2014.05.022

7. Grabarz AM, Laurent AD, Jędrzejewska B, Zakrzewska A, Jacquemin D, Ośmiałowski B (2016) The influence of the $\pi$-conjugated spacer on photophysical properties of difluoroboranyls derived from amides carrying a donor group. J Org Chem 81:2280-2292. doi:10.1021/acs.joc.5b02691

8. Boens N, Leen V, Dehaen W (2012) Fluorescent indicators based on BODIPY. Chem Soc Rev 41(3):1130-1172. doi:10.1039/C1CS15132K

9. Loudet A, Burgess K (2007) BODIPY dyes and their derivatives: syntheses and spectroscopic properties. Chem Rev 107(11):4891-4932. doi:10.1021/cr078381n

10. Ulrich G, Ziessel R, Harriman A (2008) The chemistry of fluorescent bodipy dyes: versatility unsurpassed. Angew Chem Int Ed Engl 47(7):1184-1201. doi:10.1002/anie.200702070 
11. Nepomnyashchii AB, Bard A (2012) Electrochemistry and electrogenerated chemiluminescence of BODIPY dyes. J Acc Chem Res 45(11):1844-1853. doi:10.1021/ar200278b

12. Treibs A, Kreuzer F-H (1968) Difluorboryl-komplexe von di- und tripyrrylmethenen. Justus Liebigs Ann Chem 718(1):208-223. doi:10.1002/jlac19687180119

13. Xu S, Evans RE, Liu T, Zhang G, Demas JN, Trindle CO, Fraser CL (2013) Aromatic difluoroboron $\beta$-diketonate complexes: effects of $\pi$-conjugation and media on optical properties. Inorg Chem 52(7):3597-3610. doi:10.1021/ic300077g

14. Matyjaszewski K, Davis TP (2002) Handbook of radical polymerization. Wiley, Hoboken

15. Yagci Y, Jockusch S, Turro JN (2010) Photoinitiated polymerization: advances, challenges, and opportunities. Macromolecules 43:6245-6260. doi:10.1021/ma1007545

16. Fouassier J-P, Morlet-Savary F, Lalevée J, Allonas X, Ley Ch (2010) Dyes as photoinitiators or photosensitizers of polymerization reactions. Materials 3:5130-5142. doi:10.3390/ma3125130

17. Fouassier J-P, Allonas X (2010) Basics of photopolymerization reactions. Researchsignpost, Trivandrum

18. Fouassier J-P, Lalevée J (2012) Three-component photoinitiating systems: towards innovative tailor made high performance combinations. RSC Adv 2:2621-2629. doi:10.1039/C2RA00892K

19. Doğruyol Z, Arsu N, Doğruyol SK, Pekcan Ö (2012) Critical phenomenon during photoinitiated gelation at different temperatures: a photo-DSC study. Prog Org Coat 74:181-185. doi:10.1016/j. porgcoat.2011.08.008

20. Fouassier J-P, Lalevée J (2013) Design of chromophores for photoinitiators of polymerization: brief survey and recent achievements. In: Moliere A, Vigneron E (eds) New developments in chromophore research. Nova Science Publishers, Hauppauge, pp 245-266

21. Tehfe M-A, El-Roz M, Lalevée J, Morlet-Savary F, Graff B, Fouassier J-P (2012) Bifunctional coinitiators: a new strategy for the design of efficient systems in radical photopolymerization reactions under air. Eur Polym J 48:956-962. doi:10.1016/j.eurpolymj.2012.01.022

22. Braun D (2009) Origins and development of initiation of free radical polymerization processes. Int $\mathbf{J}$ Polym Sci 2009:1-10. doi:10.1155/2009/893234

23. Xiao P, Zhang J, Dumur F, Tehfe M-A, Morlet-Savary F, Graff B, Gigmes D, Fouassier J-P, Lalevée J (2015) Visible light sensitive photoinitiating systems: recent progress in cationic and radical photopolymerization reactions under soft conditions. Prog Polym Sci 4:32-66. doi:10.1016/j. progpolymsci.2014.09.001

24. Telitel S, Blanchard N, Schweizer S, Morlet-Savary F, Graff B, Fouassier J-P, Lalevée J (2013) BODIPY derivatives and boranil as new photoinitiating systems of cationic polymerization exhibiting a tunable absorption in the 400-600 nm spectral range. Polymer 54:2071-2076. doi:10. 1016/j.polymer.2013.02.013

25. Telitel S, Lalevée J, Blanchard N, Kavalli T, Tehfe M-A, Schweizer S, Morlet-Savary F, Graff B, Fouassier J-P (2012) Photopolymerization of cationic monomers and acrylate/divinylether blends under visible light using pyrromethene dyes. Macromolecules 45:6864-6868. doi:10.1021/ ma301293m

26. Grabarz AM, Zaleśny R, Laurent AD, Jędrzejewska B, Zakrzewska A, Jacquemin D, Ośmiałowski B (2017) The influence of the $\pi$-conjugated spacer on photophysical properties of difluoroboranyls derived from amides carrying a donor group. J Org Chem 82:1529-1537. doi:10.1021/acs.joc. 5 b02691

27. Zakrzewska A, Kolehmainen E, Valkonen A, Haapaniemi E, Rissanen K, Chęcińska L, Ośmiałowski B (2013) Substituent effect in 2-benzoylmethylenequinoline difluoroborates exhibiting through-space couplings. Multinuclear magnetic resonance, X-ray diffraction, and computational study. J Phys Chem A 117(1):252-256. doi:10.1021/jp311072q

28. Ośmiałowski B, Zakrzewska A, Jędrzejewska B, Grabarz A, Zaleśny R, Bartkowiak W, Kolehmainen E (2015) Influence of substituent and benzoannulation on photophysical properties of 1-benzoylmethyleneisoquinoline difluoroborates. J Org Chem 80:2072-2080. doi:10.1021/jo502244j

29. Pietrzak M, Jędrzejewska B (2011) Synthesis of tetramethylammonium phenyltrialkylborate salts by the addition of alkyllithium reagents to a triorganylborane or organoboranylhalides. J Organomet Chem 696:2135-2141. doi:10.1016/j.jorganchem.2010.11.019

30. Wu D-E, Lu X-L, Xia M (2015) Study on the solution and solid-state fluorescence of novel $\mathrm{BF}_{2}$ complexes with (Z)-2-[phenanthridin-6(5H)-ylidene]-1-phenylethanone and its derivatives as ligands. New J Chem 39:6465-6473. doi:10.1039/C5NJ00926J 
31. Zhang S, Li B, Tang L, Wang X, Liu D, Zhou Q (2001) Studies on the near infrared laser induced photopolymerization employing a cyanine dye-borate complex as the photoinitiator. Polymer 42:7575-7578. doi:10.1016/S0032-3861(01)00233-6

32. Jędrzejewska B (2013) Factors affecting the TMPTA radical polymerization photoinitiated by phenyltrialkylborates paired with tri-cationic hemicyanine dye. Kinetic studies. Colloid Polym Sci 291(9):2225-2236. doi:10.1007/s00396-013-2964-3

33. Jędrzejewska B, Pietrzak M (2012) Applicability of hemicyanine phenyltrialkylborate salts as freeradical photoinitiators in the visible-light polymerization of acrylate. J Appl Polym Sci 123:3535-3544. doi:10.1002/app.34865

34. Tehfe MA, Louradour F, Lalevée J, Fouassier J-P (2013) Photopolymerization reactions: on the way to a green and sustainable chemistry. Appl Sci 3:490-514. doi:10.3390/app3020490

35. Pączkowski J (2006) Electron-transfer photoinitiators of free radical polymerization. The effect of the co-iniciator structure on photoinitiation ability. In: Fouassier JP (ed) Photochemistry and UV curing: new trends. Research Signpost, Kerala, pp 101-116

36. Marcus RA (1965) On the theory of electron transfer reactions. VI. Unified treatment for homogeneous and electrode reactions. J Chem Phys 43:679-701. doi:10.1063/1.1696792

37. Rehm D, Weller A (1970) Kinetics of fluorescence quenching by electron and hydrogen-atom transfer. Isr J Chem 8:259-271. doi:10.1002/ijch.197000029

38. Keskin S, Jockusch S, Turro NJ, Arsu N (2008) Electron spin resonance and laser flash photolysis study of radical addition to vinyl acrylate and related alkenes. Macromolecules 41:4631-4634. doi:10.1021/jp011813s

39. Zhang J, Campolo D, Dumur F, Xiao P, Fouassier JP, Gigmes D, Lalevée J (2015) Iron complexes as photoinitiators for radical and cationic polymerization through photoredox catalysis processes. J Polym Sci Part A Polym Chem 53:42-49. doi:10.1002/pola.27435

40. Odian G (1991) Principles of polymerization, 3rd edn. Wiley, New York, p 206

41. Jiang X, Xu H, Yin J (2004) Polymeric amine bearing side-chain thioxanthone as a novel photoinitiator for photopolymerization. Polymer 45:133-140. doi:10.1016/j.polymer.2003.10.058

42. Chatterjee S, Davis PD, Gottschalk P, Kurz ME, Sauerwein B, Yang X, Schuster GB (1990) Photochemistry of carbocyanine alkyltriphenylborate salts: intra-ion-pair electron transfer and the chemistry of boranyl radicals. J Am Chem Soc 112(17):6329-6338. doi:10.1021/ja00173a022

43. Chatterjee S, Gottschalk P, Davis PD, Schuster GB (1988) Electron-transfer reactions in cyanine borate ion pairs: photopolymerization initiators sensitive to visible light. J Am Chem Soc 110:2326-2328. doi:10.1021/ja00215a067

44. Pozdnyakov IP, Aksenova YuV, Ermolina EG, Melnikov AA, Kuznetsova RT, Grivin VP, Plyusnin VF, Berezin MB, Semeikin AS, Chekalin SV (2013) Photophysics of diiodine-substituted fluorinated boron-dipyrromethene: a time resolved study. Chem Phys Lett 585:49-52. doi:10.1016/j.cplett.2013. 08.032

45. Yang W, Karatay A, Zhao J, Song J, Zhao L, Xing Y, Zhang C, He C, Yaglioglu HG, Hayvali M, Elmali A, Küçüköz B (2015) Near-IR broadband-absorbing trans-bisphosphine Pt(II) bisacetylide complexes: preparation and study of the photophysics. Inorg Chem 54:7492-7505. doi:10.1021/acs. inorgchem.5b01107

46. Zhang C, Zhao J, Wu S, Wang Z, Wu W, Ma J, Guo S, Huang L (2013) Intramolecular RET enhanced visible light-absorbing Bodipy organic triplet photosensitizers and application in photooxidation and triplet-triplet annihilation upconversion. J Am Chem Soc 135:10566-10578. doi:10. 1021/ja405170j

47. Yang P, Zhao J, Wu W, Yu X, Liu Y (2012) Accessing the long-lived triplet excited states in Bodipyconjugated 2-(2-hydroxyphenyl) benzothiazole/benzoxazoles and applications as organic triplet photosensitizers for photooxidations. J Org Chem 77:6166-6178. doi:10.1021/jo300943t

48. Huang L, Yang W, Zhao J (2014) Switching of the triplet excited state of styryl 2,6-diiodo-Bodipy and its application in acid-activatable singlet oxygen photosensitizing. J Org Chem 79:10240-10255. doi:10.1021/jo5019014

49. Zhang C, Zhao J, Cui X, Wu X (2015) Thiol-activated triplet-triplet annihilation upconversion: study of the different quenching effect of electron acceptor on the singlet and triplet excited states of Bodipy. J Org Chem 80:5674-5686. doi:10.1021/acs.joc.5b00557

50. Xu K, Xie Y, Cui X, Zhao J, Glusac KD (2015) DiiodoBodipy-rhodamine dyads: preparation and study of the acid-activatable competing intersystem crossing and energy transfer processes. J Phys Chem B 119:4175-4187. doi:10.1021/jp509858t 
51. Wu W, Zhao J, Guo H, Sun J, Ji S, Wang Z (2012) Long-lived room-temperature near-IR phosphorescence of BODIPY in a visible-light-harvesting $\mathrm{N}^{\wedge} \mathrm{C}^{\wedge} \mathrm{N} \mathrm{Pt}^{\mathrm{II}}$-acetylide complex with a directly metalated BODIPY chromophore. Chem Eur J 18:1961-1968. doi:10.1002/chem.201102634

52. Huang L, Yu X, Wu W, Zhao J (2012) Styryl Bodipy-C $\mathrm{C}_{60}$ dyads as efficient heavy-atom-free organic triplet photosensitizers. Org Lett 14:2594-2597. doi:10.1021/ol3008843

53. Huang L, Zhao J, Guo S, Zhang C, Ma J (2013) Bodipy derivatives as organic triplet photosensitizers for aerobic photoorganocatalytic oxidative coupling of amines and photooxidation of dihydroxylnaphthalenes. J Org Chem 78:5627-5637. doi:10.1021/jo400769u

54. Fouassier J-P, Allonas X, Burget D (2003) Photopolymerization reactions under visible lights: principle, mechanisms and examples of applications. Prog Org Coat 47:16-36. doi:10.1016/S03009440(03)00011-0 